\title{
Optimization of Waltheria indica Seed Dormancy Relief Treatments and Seed Storage Parameters
}

\author{
Scott B. Lukas ${ }^{1}$, Joseph DeFrank, and Orville C. Baldos \\ Department of Tropical Plant and Soil Sciences, University of Hawaii at \\ Manoa, St. John Plant Science Lab 102, 3190 Maile Way, Honolulu, HI \\ 96822
}

Additional index words. Hawaii, native, scarification, germination

\begin{abstract}
In Hawaii, Waltheria indica (uhaloa) has been identified for expanded usage as a roadside groundcover in lowland dry ecosystems. Seed dormancy through lack of germination of viable seeds was identified in uhaloa. The presence of physical dormancy in uhaloa seeds was determined and dormancy relief methods were evaluated including hand scarification, dry heat temperature exposure, hot water exposure, and mechanical abrasion in an electric drum scarifier. As a compliment to dormancy relief, long-term storage parameters were evaluated for scarified and nonscarified seeds. The elucidation of physical dormancy was determined through hand scarification, resulting in $96 \%$ germination compared with $8 \%$ of nonscarified seeds, but is not practical on a large-scale basis. The greatest practical dormancy relief was achieved with a mechanical electric drum scarifier lined with 80-grit sandpaper for a duration of 15 or 30 seconds producing $\mathbf{9 5 \%}$ and $99 \%$ germination, respectively. Seeds immersed in boiling water for 3 and 5 seconds resulted in $\mathbf{5 8 . 6 \%}$ and $\mathbf{5 7 . 7 \%}$ germination, respectively. Dormancy relief through dry heat exposure was inferior to other relief methods, producing $39 \%$ germination at $75{ }^{\circ} \mathrm{C}$ for 60 minutes. Nonscarified seeds exhibited minimal loss of viability during 10 months of storage at $5{ }^{\circ} \mathrm{C}$ at $12 \%$ and $50 \%$ relative humidity (RH), but a significant decline in viability of scarified seeds was detected.
\end{abstract}

Plants produce seeds to ensure the greatest establishment and survival success for future generations (Stoehr and El-Kassaby, 2011). One innate mechanism to increase seedling success is seed dormancy. The critical function of dormancy is to prevent germination when conditions are suitable but when the probability of survival and growth of the seedling is low (Fenner and Thompson, 2005). Generally accepted classification systems define five classes of seed dormancy: physiological dormancy (PD), morphological dormancy, morphophysiological dormancy (MPD), physical dormancy (PY), and combinational dormancy (PY + PD) (Baskin and Baskin, 2004).

Uhaloa [Waltheria indica L. (Malvaceae)] is a pantropical shrub species which occurs in diverse populations in the Americas, Mexico, and Brazil (Wagner et al., 1990). Uhaloa in Hawaii is widely classified as a native plant, postulating that the small seeds may have attached to birds that distributed the species to the archipelago (Wester, 1992). Hawaiian uhaloa has been reported in

Received for publication 23 Feb. 2016. Accepted for publication 16 June 2016 .

This paper is a portion of a doctoral dissertation submitted by Scott B Lukas at the University of Hawaii at Manoa.

We would like to thank the Hawaii Department of Transportation for providing funding for this research.

${ }^{1}$ Corresponding author. E-mail: scott.lukas@, oregonstate.edu. to break dormancy in seeds of this species (Baskin et al., 2004). One treatment involved mechanically scarifying seeds, after 2 weeks of incubation; seeds that were mechanically scarified had germinated to $96 \%$ to $100 \%$ in light (Baskin et al., 2004). Nonscarified seeds, on the other hand, germinated to only $0 \%$ and $1 \%$ in light and darkness, respectively (Baskin et al., 2004). Other methods use to scarified seeds involve exposure to dry heat at a range of 80 to $160{ }^{\circ} \mathrm{C}$, emersion in boiling water and exposing seeds to low $\mathrm{RH}$ conditions (Baskin et al., 2004).

Baskin suggests that storage can be used as a dormancy-breaking treatment, but it can also play a fundamental role in optimizing seed longevity. To maximize the usefulness of seeds, it is necessary to understand how possible dormancy relief conditions and long-term storage potential can be achieved through specified storage parameters. Ultimately, seed survival through storage is directly related to the time the seed has been exposed to unfavorable conditions of temperature or humidity (Barton, 1961).

The impact of storage conditions on nonscarified PY dormant Cassia angustifolia seed was determined for four levels of RH $(5.5 \%, 11 \%, 33 \%$, and $75 \%)$, established and maintained using saturated salt solutions in airtight desiccators, and three storage temperatures $\left(5{ }^{\circ} \mathrm{C}, 20{ }^{\circ} \mathrm{C}\right.$, and ambient $)$. Seed viability for $C$. angustifolia was optimized at storage temperatures of 5 and $20{ }^{\circ} \mathrm{C}$ when maintained at RH levels of $5.5 \%$ and $11 \%$, increased levels of $\mathrm{RH}$ reduced seed viability over storage time (Santhoshkumar and Veena, 2012). Baldos et al. (2014) characterized storage and after ripening parameters of the native Hawaiian grass Heteropogon contortus. Optimal dormancy relieving conditions for $H$. contortus required a $28-$ to $30-\mathrm{d}$ equilibration period in a $12 \% \mathrm{RH}$ desiccation chamber to bring seed moisture levels to $6 \%$ followed by a $30^{\circ} \mathrm{C}$ storage temperature for 9 to 12 months (Baldos et al., 2014). Although this study was conducted on a grass species with a permeable seed testa, the factors of RH and temperature over time can be applicable for PY dormant seeds which have been scarified before storage.

The assessment of water imbibition can be used to elucidate physical dormancy in seeds (Rolston, 1978). The objectives of this study were to 1) evaluate physical dormancy breaking mechanisms of uhaloa seeds by evaluating seed germination in response to manual and mechanical scarification and exposure to dry heat and hot water emersion and 2) determine the impact of storage humidity and duration at $5{ }^{\circ} \mathrm{C}$ on viability and germination response of nonscarified and scarified uhaloa seeds.

\section{Materials and Methods}

than with the nontreated seeds (Boyd and Serafini, 1992). Physical dormancy has been well documented in the native Hawaiian plant Dodonaea viscosa, having similarities to the water-impermeable seedcoat of uhaloa and various physical treatments were tested
Plant material. Uhaloa seeds used in this study were derived from two separate harvests/seed batches and represented in two repeated runs of the experiments conducted. 
Seed batch one (SB1) was harvested on the Island of Molokai by the U.S. Department of Agriculture (USDA), Natural Resource Conservation Service, Hoolehua Plant materials center in July 2012 (Sakamoto, personal communication). Seed batch two (SB2) was harvested from the same USDA facility in Mar. 2014. Postharvest handling of both seed batches consisted of air drying, packaging, and $5{ }^{\circ} \mathrm{C}$ refrigeration until use (Duvachelle, personal communication). All experiments were initiated first with SB1 between the dates Sept. 2013 to Apr. 2014. SB2 experimentation was initiated between the dates of Apr. to May 2014.

For all dormancy relief studies, experimental units consisted of 50 seeds exposed to the experimental treatment/treatment combinations with four replications, repeated for each seed batch. When statistically significant results were detected, means were separated using Tukey's honestly significant difference test at $\alpha=0.05$. Each experimental unit was incubated in $90-\mathrm{mm}$ petri dishes premoistened with 3-mL distilled water and lined with filter paper (Whatman no. 2, Little Chalfont, Buckinghamshire). Petri dishes were placed in an alternating temperature germination chamber with four T5 high-output 24-W 6400-K AgroBrite bulbs (Hydrofarm, Petaluma, CA) for $14 \mathrm{~h}$ of light at $28^{\circ} \mathrm{C}$ and $10 \mathrm{~h}$ of dark at $24{ }^{\circ} \mathrm{C}$ Experimental conditions of temperature and $\mathrm{RH}$ during the seed germination period were monitored with a Hobo UX100 logger (Onset, Cape Cod, MA). Distilled water was added to petri dishes as needed over the 10-d germination period. Germination was recorded when the seed radicle protruded $1 \mathrm{~mm}$ from the seed testa.

Seed batch viability testing. In both seed batches (SB1 and SB2) experimental units were sampled from the larger stock batches following standardized sampling procedures (Elias et al., 2012). Seeds were subjected to viability testing using standard $1 \%$ tetrazolium chloride method (Elias et al., 2012; ISTA, 2003). Data were analyzed as a random complete block design in the statistical program JMP Pro 11 (SAS Institute Inc., Cary, NC).

Dormancy relief using hand cut mechanical scarification. Uhaloa seeds were hand scarified using a scalpel, with visual guidance provided with $\times 20$ magnification under a dissection microscope to remove a small piece of testa exposing unaffected endosperm. The experimental units for both seed batches were sampled following techniques outlined by Elias et al. (2012). Data were analyzed as a split-plot design in the statistical program JMP Pro 11. The main plot effect was seed batch, and the split-plot effect was hand scarification (Jones and Nachtsheim, 2009).

Dormancy relief through exposure to dry heat. Seed germination response to dry heat temperatures of $50,75,100$, and $125^{\circ} \mathrm{C}$, in a Quincy laboratory model 40GC laboratory oven (Quincy Laboratory Inc., Chicago, IL) and exposure times $(0,1,5,15,30$, and
$60 \mathrm{~min}$ ) were determined. During the seed exposure time, oven temperature was manually recorded with a thermometer. After each exposure interval, seeds were allowed to cool to room temperature for $1 \mathrm{~min}$ before the start of the seed germination phase of the experiment. Data were analyzed as a split-splitplot design in the statistical program JMP Pro 11. The main plot effect was seed batch, the split-plot effect was oven temperature and the split-split-plot effect was duration exposed to treatment temperatures.

Dormancy relief effect through exposure to boiling water. The relief of physical dormancy was evaluated by exposing uhaloa seeds to a range of boiling water emersion times. Seed experimental units were dipped in boiling distilled water for $0,1,3,5,10,15$, 30 , or $60 \mathrm{~s}$. All experimental treatments and the control were dipped in distilled ice water for $5 \mathrm{~s}$ to cool the seeds and placed in a petri dish lined with filter paper with $3 \mathrm{~mL}$ of distilled water. The hot water bath temperature was measured to quantify temperatures and a stir bar was used to ensure a homogenous heated water solution. The water temperature was held constant at $101{ }^{\circ} \mathrm{C}$ throughout the entire experiment and the cold water bath ranged from 12.5 to $14.0^{\circ} \mathrm{C}$. Seeds that did not germinate were visually inspected to determine if water imbibition occurred and for the presence of seed deterioration through rotting. Data were analyzed as a split-plot design in the statistical program JMP Pro 11. The main plot effect was seed batch and the split-plot effect was the duration of seed exposure to boiling water.

Dormancy relief using a mechanical sandpaper drum scarifier. Seed scarification was evaluated using a commercially available mechanical sandpaper scarifier to relieve physical dormancy in uhaloa seeds. Scarification was conducted in a Forsberg seed scarifier with a 1/3-horsepower electric motor (Forsberg, INC., Thief River Falls, MN). Sandpaper coarseness is classified with a Coated Abrasive Manufacturers Institute grit designation, the 80,60 , and 40 grits used have average particle diameters of 190, 265, and $425 \mu \mathrm{m}$, respectively. The experiment evaluated three grits of sandpaper $(40,60$, and 80 grit) at three exposure times of 15,30 , and $45 \mathrm{~s}$. Data were analyzed as a split-splitplot design in the statistical program JMP Pro 11. The split-split-plot model was designed with seed batch as the main plot effect, sandpaper coarseness as the split-plot effect and duration in the scarifier as the split-splitplot effect.

Impact of storage conditions on seed viability of scarified and nonscarified seed to evaluate seed preservation. Both scarified and nonscarified seeds were partitioned into $0.25 \mathrm{~g}(\approx 200$ seeds $)$ units and placed in open $1.5-\mathrm{mL}$ microcentrifuge tubes with O-ring gasket lid (Fisher Scientific, Pittsburgh, PA). Scarified seeds were mechanically treated in a Forsberg drum scarifier lined with 80-grit sandpaper operating for a duration of 30 s. Since the seed testa of PY seed is impermeable to water vapor, the nonscarified treatments represented a control. Seeded tubes were equilibrated at two RH levels inside sealed Bel-Art (Scienceware, Wayne, $\mathrm{NJ}$ ) nonvacuum desiccation chambers. Humidity levels were set and maintained using saturated salt solutions of lithium chloride $(12 \% \mathrm{RH})$ and calcium nitrate $(50 \% \mathrm{RH})$ (Baldos et al., 2014; Greenspan, 1977). After the 28-d humidity equilibrium period, seed sample tubes were sealed and transferred to a $5{ }^{\circ} \mathrm{C}$ storage temperature. Seeds were withdrawn from the temperature chambers at intervals of 2 months with the last sample removed after 10 months. Seeds were evaluated for viability (Elias et al., 2012) and germination percentages at each time interval. Data were analyzed as a splitsplit-split plot using the general analysis of variance fit model function in the statistical software program Statistix 10.0 (Analytical Software, Tallahassee, FL). In the splitsplit-split-plot model statement, seed batch was the main plot effect, scarification the split-plot effect, storage humidity the splitsplit-plot effect, and months of storage as the split-split-split-plot effect. Treatment response data included seed viability and percent germination. Nonscarified seeds were evaluated for germination at each storage interval to determine if dry storage alone could impact the physical dormancy imposed by the seedcoat.

\section{Results}

Seed batch viability testing. Tetrazolium testing for seed viability indicated that $96.3 \%$ of seeds sampled from SB1 were viable with a significantly lower level of $62.5 \%$ recorded for SB2. Viability values for both seed batches will be used to standardize germination results in subsequent dormancy trials using the equation:

\section{Percent standardized germination

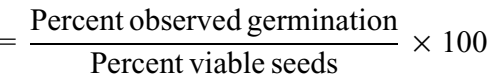

Dormancy relief through hand cut mechanical scarification. There was no interaction between the factors of seed batches and cutting treatment $(P=0.74)$, allowing for the pooling of treatment means across the factor of seed batch (Gomez and Gomez, 1984). Hand cut treatments resulted in an average germination of $96 \%$ compared with $8 \%$ of nonscarified treatments $(P<0.001)$.

Dormancy relief effect through exposure to dry heat. There was no significant interaction between the factors of seed batch $x$ temperature $\times$ duration $(P=0.0718)$; however, a significant interaction between temperature $\times$ duration $(P=<0.0001)$ was detected. The treatment that resulted in the significantly highest germination was exposed to a temperature of $75^{\circ} \mathrm{C}$ for $60 \mathrm{~min}$, with a mean germination of $39.4 \%$. Treatments exposed to $75{ }^{\circ} \mathrm{C}$ for 30 and $15 \mathrm{~min}$ were significantly lower than the 60 -min treatment but provided the second and 
Table 1. Germination means (\%) of uhaloa seeds exposed to four dry heat treatments over six durations.

\begin{tabular}{lccrrrr}
\hline & \multicolumn{7}{c}{ Duration $(\min )^{z, y}$} \\
\cline { 2 - 7 } Temperature $\left({ }^{\circ} \mathrm{C}\right)$ & 0 & 1 & 5 & 15 & 30 & 60 \\
\hline 50 & $8.6 \mathrm{~d}$ & $17.0 \mathrm{c}$ & $20.0 \mathrm{c}$ & $18.7 \mathrm{c}$ & $18.2 \mathrm{c}$ & $18.4 \mathrm{c}$ \\
75 & $9.5 \mathrm{~d}$ & $19.2 \mathrm{c}$ & $20.0 \mathrm{c}$ & $23.7 \mathrm{bc}$ & $27.7 \mathrm{~b}$ & $39.4 \mathrm{a}$ \\
100 & $8.4 \mathrm{~d}$ & $22.0 \mathrm{bc}$ & $19.0 \mathrm{c}$ & $9.5 \mathrm{~d}$ & $0.9 \mathrm{e}$ & $0.0 \mathrm{e}$ \\
125 & $9.5 \mathrm{~d}$ & $18.8 \mathrm{c}$ & $0.3 \mathrm{e}$ & $0.0 \mathrm{e}$ & $0.0 \mathrm{e}$ & $0.0 \mathrm{e}$ \\
\hline
\end{tabular}

${ }^{\mathrm{z}}$ Means within columns and rows followed by the same letter are not significantly different according to Tukey's honestly significant difference comparison at $P \leq 0.05$.

${ }^{\mathrm{y}}$ Means are reported from four experimental replications.
Table 2. Germination response means (\%) of uhaloa seeds exposed to $101{ }^{\circ} \mathrm{C}$ water emersion over eight durations.

\begin{tabular}{lc}
\hline Duration (s) & Germination $(\%)^{z, y}$ \\
\hline 0 & $8.8 \mathrm{e}$ \\
1 & $37.3 \mathrm{~d}$ \\
3 & $58.6 \mathrm{a}$ \\
5 & $57.7 \mathrm{ab}$ \\
10 & $50.2 \mathrm{bc}$ \\
15 & $46.5 \mathrm{c}$ \\
30 & $43.7 \mathrm{~cd}$ \\
60 & $38.8 \mathrm{~d}$ \\
\hline
\end{tabular}

${ }^{\mathrm{z}}$ Means followed by the same letter are not significantly different according to Tukey's honestly significant difference comparison at $P \leq 0.05$.

${ }^{\mathrm{y}}$ Means are reported from four experimental replications.

third numerically highest germination. Minor stimulation in germination was recorded in treatments exposed to $50{ }^{\circ} \mathrm{C}$. The $75^{\circ} \mathrm{C}$ treatments exhibited a general positive linear trend until the maximum germination treatment. Nongerminated seeds exposed to low temperature treatments $\left(50\right.$ and $\left.75{ }^{\circ} \mathrm{C}\right)$ remained viable, with no disruption to the mechanism of PY. Temperature exposure of $100{ }^{\circ} \mathrm{C}$ resulted in stimulation at $1 \mathrm{~min}$ of exposure, then decreased steadily to zero germination at 30 min of exposure. A similar effect occurred at $125^{\circ} \mathrm{C}$ in which stimulation occurred at $1 \mathrm{~min}$ of exposure then rapidly decreased to zero germination at $5 \mathrm{~min}$ (Table 1).

Dormancy relief effect through exposure to boiling water. There was no significant interaction detected between the factors of seed batch $\times$ treatment $(P=0.7719)$, therefore treatment means will be pooled for the factor of seed batch. All boiling treatments resulted in significantly greater germination than the untreated seeds. Optimal germination was found at a boiling duration of 3 and $5 \mathrm{~s}$, with $58.6 \%$ and $57.7 \%$ germination, respectively. creased until the final 60 -s duration, resulting in $38.8 \%$ germination (Table 2). The reduced germination and subsequent viability loss at longer exposure durations was attributed to seed death due to overheating and was confirmed visually by the presence water saturated rotting endosperms.

Dormancy relief using mechanical sandpaper drum scarifier. There was a significant interaction between the factors of seed batch $\times$ sandpaper $\times$ exposure time $(P=$ 0.001 ), thus the results will be presented for each seed batch. In both seed batches, the highest level of germination occurred with Germination decreased as exposure times in- 80-grit sandpaper exposed at 15 and $30 \mathrm{~s}$, although the 30 -s treatment in both seed batches was numerically optimal. As exposure duration increased, especially as sandpaper grit decreased (more coarse particles) seeds were pulverized causing endosperm and embryo damage, lowering germination and viability rates. The decrease in germination due to damage was more pronounced in SB2 compared with SB1 (Table 3).

Impact of storage conditions on seed viability of scarified and nonscarified seed to evaluate seed preservation. A significant interaction was detected between the factors of seed batch $\times$ scarification $\times$ month, therefore results are presented for each seed batch $(P=0.032)$, pooled over both humidity levels. Within SB1 the highest seed viability was found at month 0 (start of trial) in both the scarified and nonscarified treatments ( $95 \%$ and $98 \%$, respectively). In nonscarified treatments, viability decreased to $92 \%$ at month 10 . Scarification significantly reduced viability after month 2 of storage until month 10 ( $92 \%$ to $71 \%$, respectively) (Table 4$)$. In SB2, there was no viability loss with storage of nonscarified seeds. Scarified seeds from SB2 followed a similar pattern of viability loss as seeds from SB1 (i.e., $\approx 25 \%$ loss in viability with scarification and 10 months of storage).

In SB2, the highest seed viability was recorded at month 0 in the scarified treatment $(65 \%)$. Seed viability remained stable throughout the 10 months of storage for the nonscarified seeds (Table 4). Scarified seeds lost viability significantly with time from month 2 until month 10 (58\% to $40 \%$, respectively). The decline recorded in viability in the scarified treatments over the durations in both seed batches indicate that scarification before storage is not recommended. Humidity levels evaluated during storage did not have a significant effect on seed viability. Since viability in nonscarified seeds remained constant during storage, germinarelief was occurring over storage duration. The analysis indicated that there was no significant interaction between the factors of seed batch $\times$ months $(P=0.199)$, therefore results will be pooled over seed batch. Analysis of germination data of nonscarified seeds indicated a slight reduction from month 0 until month 10 (7.5\% to $5 \%$, respectively). Nonscarified seeds are not relieved of dormancy over storage durations up to 10 months (Table 5).

\section{Discussion}

Seed viability was seen to have differed significantly between the two seed batches used throughout the range of experiments conducted. Uhaloa seed harvested by the USDA Hoolehua Plant Materials Center in 2012 (SB1) was considered "late" (Sakamoto, personal communication), as a result seeds were mostly mature and shattering from the mother plants. For the 2014 seed batch (SB2), harvest timing was considered earlier than the 2012 harvest time resulting in a larger percentage of immature seed with potentially thinner seedcoats. The 2012 harvest yielded $1.8 \mathrm{~kg}$ of seed compared with the 2014 harvest of $11.3 \mathrm{~kg}$, from the same field with $\approx 800$ harvested plants. The harvester combine (Massey Ferguson MF-17/19; Kincade Equipment Manufacturing, Haven, KS) used to collect seeds from the field, used settings that changed between the 2012 and 2014 harvests. For the 2014 seed harvest, the alteration reduced the gap between the thresher wheel and the concave of the combine, causing more mechanical damage to the seeds harvested (Duvachelle, personal communication). The reduced viability in the 2014 seed batch was attributed to the combination of the greater percentage of immature seeds and more physical damage during harvesting.

Dormancy was determined to be physically imposed based on the results of the hand cutting of uhaloa seeds; however, the time to hand scarify 200 seeds is not practical for any large-scale seed processing. Optimization of the dormancy relief methods proved to be most effective and efficient in both seed batches using an electric drum sandpaper scarifier with 80 -grit sandpaper for a duration of $30 \mathrm{~s}$. Using sandpaper for seed scarification to relieve physical dormancy is well tion was analyzed to determine if dormancy

Table 3. Germination means (\%) for two seed batches (SB1 and SB2) of uhaloa seeds exposed to mechanical abrasion in a sandpaper scarifier with three levels of sandpaper grit and four exposure durations.

\begin{tabular}{|c|c|c|c|c|c|c|c|c|}
\hline \multirow{3}{*}{$\begin{array}{l}\text { Treatment } \\
\text { sandpaper (grit) }\end{array}$} & \multicolumn{8}{|c|}{ Duration $(\mathrm{s})^{\mathrm{z}, \mathrm{y}}$} \\
\hline & \multicolumn{2}{|c|}{0} & \multicolumn{2}{|c|}{15} & \multicolumn{2}{|c|}{30} & \multicolumn{2}{|c|}{45} \\
\hline & SB1 & SB2 & SB1 & SB2 & SB1 & SB2 & SB1 & SB2 \\
\hline$\overline{40}$ & $13.5 \mathrm{~g}$ & $12.8 \mathrm{~g}$ & $79.4 \mathrm{~b}$ & 77.1 & $74.3 \mathrm{~b}$ & $29.6 \mathrm{de}$ & $27.5 \mathrm{ef}$ & $16.0 \mathrm{fg}$ \\
\hline 60 & $14.0 \mathrm{~g}$ & $9.9 \mathrm{~g}$ & $76.4 \mathrm{~b}$ & $80.4 \mathrm{~b}$ & $81.5 \mathrm{~b}$ & $40.8 \mathrm{~cd}$ & $45.7 \mathrm{c}$ & $17.6 \mathrm{efg}$ \\
\hline 80 & $13.5 \mathrm{~g}$ & $9.7 \mathrm{~g}$ & $95.2 \mathrm{a}$ & $94.5 \mathrm{a}$ & $97.1 \mathrm{a}$ & $98.4 \mathrm{a}$ & $71.7 \mathrm{~b}$ & $42.4 \mathrm{c}$ \\
\hline
\end{tabular}

${ }^{\mathrm{z}}$ Means within rows and columns followed by the same letter are not significantly different according to Tukey's honestly significant difference comparison at $P \leq 0.05$.

${ }^{y}$ Means are reported from four experimental replications. 
Table 4. Seed viability means (\%) of scarified and nonscarified uhaloa seeds over 10 month of storage at $5{ }^{\circ} \mathrm{C}$, represented for seed batch one and two.

\begin{tabular}{lcccccc}
\hline & \multicolumn{5}{c}{ Months of storage (seed batch 1) } \\
\cline { 2 - 7 } Seed treatment & 0 & 2 & 4 & 6 & 8 & 10 \\
\hline Nonscarified & $97.8 \mathrm{a}$ & $95.4 \mathrm{ab}$ & $93.3 \mathrm{ab}$ & $94.3 \mathrm{ab}$ & $93.1 \mathrm{ab}$ & $92.4 \mathrm{bc}$ \\
Scarified & $95.4 \mathrm{ab}$ & $91.5 \mathrm{bc}$ & $87.1 \mathrm{c}$ & $80.6 \mathrm{~d}$ & $77.1 \mathrm{~d}$ & $70.5 \mathrm{e}$ \\
& \multicolumn{7}{c}{ Months of storage (seed batch 2) } \\
\cline { 2 - 7 } & 0 & 2 & 4 & 6 & 8 & 10 \\
\hline Seed treatment & $62.1 \mathrm{fg}$ & $62.9 \mathrm{fg}$ & $61.4 \mathrm{fg}$ & $61.3 \mathrm{fg}$ & $61.7 \mathrm{fg}$ & $61.5 \mathrm{fg}$ \\
Nonscarified & $64.8 \mathrm{f}$ & $57.9 \mathrm{gh}$ & $53.5 \mathrm{hi}$ & $50.6 \mathrm{i}$ & $50.0 \mathrm{i}$ & $39.6 \mathrm{j}$ \\
\hline
\end{tabular}

${ }^{z}$ Means within rows and columns followed by the same letter are not significantly different according to Tukey's honestly significant difference comparison at $P \leq 0.05$.

${ }^{y}$ Means are reported from four experimental replications.

Table 5. Germination means (\%) for storage potential of nonscarified uhaloa seeds over 10 month, pooled over two seed batches.

\begin{tabular}{cc}
\hline Months & Germination $(\%)^{z, y}$ \\
\hline 0 & $7.5 \mathrm{a}$ \\
2 & $7.0 \mathrm{ab}$ \\
4 & $5.5 \mathrm{ab}$ \\
6 & $5.8 \mathrm{ab}$ \\
8 & $5.6 \mathrm{ab}$ \\
10 & $5.0 \mathrm{~b}$ \\
\hline
\end{tabular}

${ }^{\mathrm{z}}$ Means followed by the same letter are not significantly different according to Tukey's honestly significant difference comparison at $P \leq 0.05$.

${ }^{\mathrm{y}}$ Means are reported from four experimental replications.

established (Egley, 1979; Hutchison and Ashton, 1979), but customizing the technique to a species-specific regime is imperative (Olszewski et al., 2010).

Storage parameters evaluating the effects of seeds scarified and nonscarified over a 10-month duration was designed to streamline the process of scarification and storage. The intent of this experiment was to enable to end user of the seeds a more streamline process, where seed could be immediately ready for use on removal from storage. However, the decline in seed viability over 10 months with scarified seeds indicates this procedure is not recommended for long-term storage after 2 months. On the basis of treatments evaluated, viability of uhaloa seed is maintained at high levels when nonscarified seeds are stored at $5{ }^{\circ} \mathrm{C}$ at both $12 \%$ and $50 \%$ equilibrated $\mathrm{RH}$ for up to 10 months. The duration of storage of SB1 at $5{ }^{\circ} \mathrm{C}$ before initiation of experimentation further indicates the ability for nonscarified seeds to be stored for extended periods without a significant loss of viability.

The research presented here supports the following protocols for the utilization of uhaloa from seed stock. If seeds are not needed immediately after harvest, store at $5{ }^{\circ} \mathrm{C}$ at either $12 \%$ or $50 \% \mathrm{RH}$. When seeds are desired for use, scarify using an electric drum scarifier with 80-grit sandpaper for a duration of $30 \mathrm{~s}$ to relieve physical dormancy. Once the seeds are scarified, viability will decline significantly after 2 months of storage at low temperatures.

\section{Literature Cited}

Baldos, O.C., J. DeFrank, M. Kramer, and G.S. Sakamoto. 2014. Storage humidity and temperature affect dormancy loss and viability of tanglehead (Heteropogon contortus) seeds. HortScience 49:1328-1334.

Barton, L.V. 1961. Seed preservation and longevity. Leonard Hill, London, and Interscience Publishers, NY.

Baskin, C.C. 2003. Breaking physical dormancy in seeds-focussing on the lens. New Phytol. 158:229-232.

Baskin, J.M. and C.C. Baskin. 2004. A classification system for seed dormancy. Seed Sci. Res. 14:1-16.

Baskin, J.M., B.H. Davis, C.C. Baskin, S.M. Gleason, and S. Cordell. 2004. Physical dormancy in seeds of Dodonaea viscosa (Sapindales, Sapindaceae) from Hawaii. Seed Sci. Res. 14:81-90.

Boyd, R.S. and L.L. Serafini. 1992. Reproductive attrition in the rare chaparral shrub Fremontodendron decumbens lloyd (Sterculiaceae). Amer. J. Bot. 79:1264-1272.

Egley, G. 1979. Seed coat impermeability and germination of showy crotalaria (Crotalaria spectabilis) seeds. Weed Sci. 27:355-361.
Elias, S.G., L.O. Copeland, and M.B. McDonald. 2012. Seed testing: Principles and practices. Michigan State Univ. Press, East Lansing, MI.

Fenner, M. and K. Thompson. 2005. The ecology of seeds. Cambridge Univ. Press, Cambridge, UK.

Gomez, K.A. and A.A. Gomez. 1984. Statistical procedures for agricultural research. Wiley, New York, NY.

Greenspan, L. 1977. Humidity fixed points of binary saturated aqueous solutions. J. Res. Natl. Bur. Stand. 81:89-96.

Howard, R.A. 1974. Flora of the Lesser Antilles: Leeward and windward islands. Arnold Arboretum, Harvard Univ., Jamaica Plain, MA.

Howard, R.A. 1988. Flora of the Lesser Antilles. Leeward and windward islands. Arnold Arboretum, Harvard Univ., Jamaica Plain, MA.

Hutchison, J.M. and F.M. Ashton. 1979. Effect of desiccation and scarification on the permeability and structure of the seed coat of Cuscuta campestris. Amer. J. Bot. 66:40-46.

ISTA. 2003. International rules for seed testing. International Seed Testing Association, Zurich, Switzerland.

Jones, B. and C.J. Nachtsheim. 2009. Split-plot designs: What, why, and how. J. Qual. Technol. 41:340.

Long, R.W. and O. Lakela. 1971. A flora of tropical Florida; a manual of the seed plants and ferns of southern peninsular Florida. Univ. of Miami Press, Coral Gables, FL.

Olszewski, M.W., C.A. Young, and J.B. Sheffield. 2010. Germination and seedling growth of Desmanthus illinoensis and Desmodium canadense in response to mechanical scarification. HortScience 45:1554-1558.

Rolston, M.P. 1978. Water impermeable seed dormancy. Bot. Rev. 44:365-396.

Sánchez, P. and H. Uranga. 1993. Plantas indeseables de importancia económica en los cultivos tropicales. Editorial Científico-Técnica La Habana.

Santhoshkumar, G. and G. Veena. 2012. Effect of temperature and relative humidity on seed viability and storage of senna seeds. Intl. J. Plant Sci. 7:117-121.

St John, H. 1979. The vegetation of Hawaii as seen on captain Cook's voyage in 1779. Pac. Sci. 33:79-83.

Stoehr, M. and Y. El-Kassaby. 2011. Challenges facing the forest industry in relation to seed dormancy and seed quality, p. 3-15. In: A.R. Kermode (ed.). Seed dormancy. Humana Press, New York City, NY.

Wagner, W., D. Herbst, and S. Sohmer. 1990. Manual of the flowing plants of Hawaii. Univ. of Hawaii Press and Bishop Museum Press, Honolulu, HI.

Wester, L. 1992. Origin and distribution of adventive alien flowering plants in Hawaii. Alien plant invasions in native ecosystems of Hawaii. 99-154. 